\title{
Identifying 22q11.2 Deletion Syndrome and Psychosis Using Resting-State Connectivity Patterns
}

\author{
Elisa Scariati • Marie Schaer • Jonas Richiardi • \\ Maude Schneider • Martin Debbané • \\ Dimitri Van De Ville $\cdot$ Stephan Eliez
}

Received: 19 September 2013/Accepted: 12 February 2014/Published online: 22 February 2014

(c) Springer Science+Business Media New York 2014

\begin{abstract}
The clinical picture associated with 22q11.2 deletion syndrome (22q11DS) includes mild mental retardation and an increased risk of schizophrenia. While the clinical phenotype has been related to structural brain network alterations, there is only scarce information about functional connectivity in 22q11DS. However, such studies could lead to a better comprehension of the disease and reveal potential biomarkers for psychosis. A connectivity decoding approach was used to discriminate between 42 patients with 22q11DS and 41 controls using resting-state connectivity. The same method was then applied within the 22q11DS group to identify brain connectivity patterns specifically related to the presence of psychotic symptoms. An accuracy of $84 \%$ was achieved in differentiating patients with 22q11DS from controls. The discriminative
\end{abstract}

E. Scariati $(\bowtie) \cdot$ M. Schaer · M. Schneider · M. Debbané

S. Eliez

Office Médico-Pédagogique Research Unit, Department of

Psychiatry, University of Geneva School of Medicine, 1 rue

David Dufour, CP 50, 1211 Geneva 8, Switzerland

e-mail: elisa.scariati@unige.ch

M. Schaer

Stanford Cognitive and Systems Neuroscience Laboratory,

Stanford University School of Medicine, Suite 220, 1070

Arastradero Road, Palo Alto, CA 94304, USA

J. Richiardi

Laboratory for Neurology and Imaging of Cognition,

Department of Neurosciences and Department of Clinical

Neurology, University of Geneva, Geneva, Switzerland

J. Richiardi

Functional Imaging in Neuropsychiatric Disorders Laboratory,

Department of Neurology and Neurological Sciences, Stanford

University, 1215 Welch road Mod. B Rm. 47, Stanford,

CA 94305, USA connections were widespread, but predominantly located in the bilateral frontal and right temporal lobes, and were significantly correlated to IQ. An $88 \%$ accuracy was obtained for identification of existing psychotic symptoms within the patients group. The regions containing most discriminative connections included the anterior cingulate cortex (ACC), the left superior temporal and the right inferior frontal gyri. Functional connectivity alterations in 22q11DS affect mostly frontal and right temporal lobes and are related to the syndrome's mild mental retardation. These results also provide evidence that resting-state connectivity can potentially become a biomarker for psychosis and that ACC plays an important role in the development of psychotic symptoms.

\author{
M. Debbané \\ Adolescence Clinical Psychology Research Unit, Faculty of \\ Psychology and Educational Sciences, University of Geneva, \\ Geneva, Switzerland \\ D. Van De Ville \\ Department of Radiology and Medical Informatics, University of \\ Geneva, Geneva, Switzerland \\ D. Van De Ville \\ Medical Image Processing Lab, Institute of Bioengineering, \\ Ecole Polytechnique Féderale de Lausanne, Lausanne, \\ Switzerland \\ S. Eliez \\ Department of Genetic Medicine and Development, University \\ of Geneva School of Medicine, Geneva, Switzerland
}


Keywords 22q11DS - Resting-state networks - Brain connectivity decoding $\cdot$ Schizophrenia $\cdot$ Early psychosis

\section{Introduction}

Accumulating evidence suggests that both cognitive and psychiatric disabilities can be linked to altered patterns of brain connectivity (Buckholtz and Meyer-Lindenberg 2012; Bullmore and Sporns 2009). Indeed, cognitive functions do not depend only on the independent functioning of specialized brain regions but also on the their connectivity and capacity of integration (Bullmore and Sporns 2009; Sporns et al. 2005). For instance brain networks alterations have already been linked to differences in cognitive abilities (Li et al. 2009; van den Heuvel et al. 2009; Wu et al. 2013; Cole et al. 2012) and to several psychiatric disorders including Alzheimer disease (Filippi and Agosta 2011; Greicius 2008), depression (Greicius 2008), and schizophrenia (Karbasforoushan and Woodward 2012).

The 22q11.2 deletion syndrome (22q11DS) is caused by a microdeletion spanning 1.5-3 Mb located on the chromosome 22 (Lindsay et al. 1995). Apart from the somatic consequences of this deletion, the disorder is characterized by a high incidence of cognitive and psychiatric disabilities (Baker and Vorstman 2012), including notably a mild decrease in IQ (Antshel et al. 2008a) and a high prevalence of psychotic symptoms (Baker and Skuse 2005) and schizophrenia (Murphy et al. 1999). In this disorder, structural alterations of the brain networks are sustained by white matter alterations including a well described 11-16 \% loss of volume (Simon et al. 2005; Eliez et al. 2000) and widespread microstructural defects (Sundram et al. 2010; Barnea-Goraly et al. 2003; da Silva et al. 2011; Simon et al. 2008) that have furthermore been associated to various cognitive deficiencies (Radoeva et al. 2012; Barnea-Goraly et al. 2005; Simon et al. 2008) and psychiatric symptoms (Radoeva et al. 2012) including schizotypal traits (Sundram et al. 2010). The alteration of the structural wiring of the brain in 22q11DS has recently been confirmed using tractography (Ottet et al. 2013a).

In line with these results, we have previously shown the presence of functional connectivity alterations at rest in youths with 22q11DS (Debbane et al. 2012). Part of these alterations was related to impulsivity and attention deficits and to the presence of psychotic symptoms. More recently, another group has studied resting-state connectivity in 22q11DS and described relationships between functional connectivity alterations and impairments in social skills (Schreiner et al. 2013). As resting-state fMRI (rs-fMRI) records spontaneous brain activity (Fox and Raichle 2007), it is particularly adapted to study brain function in populations with mental retardation. However, to the best of our knowledge, there is no other study to date that explores the relationships between resting-state connectivity and psychosis in 22q11DS. Improved delineation of functional networks in this population could lead to a better understanding of the mechanisms underlying the development of schizophrenia and reveal potential biomarkers.

In this study, we investigated functional connectivity at rest using brain connectivity decoding (Richiardi et al. 2013) with a support vector machine (SVM) classifier. In comparison to massively univariate methods, that test independently each connection, this multivariate analysis identifies a specific set of connections that allow discrimination between groups. As the combination of several connectivity alterations may convey more information than each connection considered independently, this method increases sensitivity (Raizada and Kriegeskorte 2010) and avoids to make multiple statistical testing. Furthermore, contrarily to the other methods developed to correct for multiple comparisons in brain connectivity analysis (Zalesky et al. 2010; Meskaldji et al. 2011), brain connectivity decoding permits inference at the individual level, and is therefore useful to test potentials biomarkers. Brain connectivity decoding has successfully been applied for revealing mental states (Richiardi et al. 2011), studying brain connectivity development (Dosenbach et al. 2010) and identifying patients with multiple sclerosis (Richiardi et al. 2012), depression (Craddock et al. 2009), and chronic schizophrenia (Shen et al. 2010; Bassett et al. 2012; Venkataraman et al. 2012). In this study, we used rs-fMRI data obtained from 42 children, adolescents and young adults with 22q11DS and 41 age-matched controls. We expected to find widespread functional connectivity alterations, with a substantial participation of the frontal and parietal lobes in relation to the patients' cognitive deficits. We also aimed at assessing whether resting-state brain connectivity could represent a biomarker for the presence of prodromal psychosis, hypothesizing that the classifier would be able to identify the patients with 22q11DS that suffer of psychotic symptoms from the patients that do not have psychotic symptoms.

\section{Materials and Methods}

Participants

Discrimination Between Patients with 22q11DS and Healthy Controls

The patients included in this study were recruited through advertisements in family associations across French and English speaking European countries. The presence of a 
22q11.2 deletion was confirmed by a Quantitative Fluorescent Polymerase Chain Reaction performed on material obtained from a blood sample. A clinical and cognitive assessment was performed by trained clinicians and included: (1) IQ measures using the Wechsler Intelligence Scale for Children-Third Edition (Wechsler 1991) under 17 years old, and the Wechsler Adult Intelligence Scale-III (Wechsler 1997) from 17 years old; (2) screening for a schizophrenic syndrome with the Diagnostic Interview for Children and Adolescents (DICA) (Reich 2000) and the Structured Clinical Interview for DSM-IV axis I disorders, SCID (First 1997) for adults; (3) screening for the presence of a prodromal psychotic syndrome using the Structured Interview of Prodromal Symptoms (SIPS) (McGlashan et al. 2001; Miller et al. 2003). Initially scans from 64 patients aged between 9 and 30 were collected. From these scans, two were excluded because the patients fell asleep during the resting-state acquisition and two were excluded because part of the cerebral cortex was not included in the images. An additional 18 scans were discarded because the patients moved more than one voxel size $(3 \mathrm{~mm})$ in translation or $3^{\circ}$ in rotation during the resting-state sequence. In the end, the patients group used in our analysis (referred to as the 22q11DS group), comprised 42 patients (18 females) with a mean age (years) of $17.2 \pm 4.8$ and a mean full scale IQ of $66.9 \pm 11.9$. Among them, 41 were native French speakers and one was native English speaker. Three participants grew up in a bilingual family. In this group 3 patients suffered from schizophrenia, and 7 patients fulfilled the criteria for a prodromal psychotic syndrome (1 with Brief Intermittent Psychotic Syndrome, 6 with Attenuated Positive Symptoms). Seven participants did not accomplish this assessment as they were too young (under 12 years old) or had too strong cognitive deficits to reliably answer. In the 22q11DS group, 12 participants were taking one or several psychotropic medications: antidepressants (3), atypical neuroleptics (5), antiepileptics (4), methylphenidate (3) and benzodiazepines (1). The 22 patients which scans were discarded did not differ from the patients included in the study regarding mean age ( $17 \pm 4, T$ test: $p=0.9)$ but had a significantly higher mean IQ (74 $\pm 9, T$ test: $p=0.02$ ). Among them, one suffered from schizophrenia and three had a prodromal psychotic syndrome.

The control group was composed of healthy siblings of the patients and of healthy participants recruited through advertisements in public schools and community in Geneva. Only subjects without previous history of psychiatric and neurologic disorders were recruited. Initially, 47 scans were acquired for the control group, but two participants were excluded because part of the cerebral cortex was missing in the acquisition and four because of excessive movement according to the abovementioned criteria. The group included in our analysis had the same age range that the 22q11DS group (mean age: $18.2 \pm 5.4$ ) and comprised 41 participants ( 21 females). They had a mean IQ of $108 \pm 15.8$. Thirty-six of them were native French speakers, one was native English speaker and four were both French and English native speakers. In total, nine healthy controls were raised in a bilingual environment.

Half of the participants included in this study (21 controls and 21 patients) were included in our previous paper (Debbane et al. 2012). There were no significant differences between the control group and the 22q11DS group for age ( $T$ test: $p=0.38$ ) or gender distribution (Pearson $\chi^{2}$ test: $\left.p=0.4\right)$ but IQ was significantly higher in the control group ( $T$ test: $p<0.0001)$ and there was a trend for a difference in the repartition of bilingual subjects between groups (Pearson $\chi^{2}$ test: $p=0.06$ ). Written and informed consent was obtained for all the participants. The Institutional Review Board of the Geneva University School of Medicine approved the research protocol.

\section{Identification of Moderate to Severe Psychotic Symptoms Within the Patients Group}

In the 22q11DS group the presence of psychotic symptoms was defined as having a score of minimum three in one of the positive subscales of the SIPS. This threshold corresponds to the intensity of symptoms necessary to have at least an "Attenuated Positive Symptoms Prodromal Syndrome", aside the criteria of time and frequency. Among the 22q11DS group, 13 participants fulfilled the criteria for inclusion in the positive symptoms group (PS+; age range: 12-24). In order to have a comparable group without PS (PS-), we selected among the remaining patients 13 subjects that were individually matched for age and gender to the PS+ group. As there were four remaining patients within the age range of the PS+ group, we included them into the testing group of the classifier $(N=17)$. All the patients included in the PS- group were native French speakers and this group included no bilingual subjects. The PS+ group comprised one native English speaker and two bilingual subjects. In the PS - group, 3 patients were taking methylphenidate. In the PS+ group, 5 patients were taking medications including atypical neuroleptics (3), antidepressants (2), and antiepileptic (1). There was no significant difference in IQ ( $T$ test: $p=0.2$ ) or proportion of bilingual subjects (Pearson $\chi^{2}$ test: $p=0.1$ ) between the groups.

\section{MRI Acquisition}

Participants were scanned at the Geneva Center for Biomedical Imaging (CIBM), with a Siemens Trio 3T scanner. The protocol comprised a high-resolution T1-weighted 
scan $(\mathrm{TR}=2,500 \mathrm{~ms}, \mathrm{TE}=30 \mathrm{~ms}, 192$ coronal slices, slice thickness $=1.1 \mathrm{~mm}$, flip angle $=8^{\circ}$, matrix size $224 \times 256, \mathrm{FOV}=256 \times 224)$ and an 8 -minutes rs-fMRI sequence containing 200 volumes $(\mathrm{TR}=2,400 \mathrm{~ms}$, $\mathrm{TE}=30 \mathrm{~ms}, 38$ axial slices, slice thickness $=3.20 \mathrm{~mm}$, flip angle $=85^{\circ}, \quad$ matrix size $94 \times 128, \quad$ FOV $=$ $96 \times 128$ ). During the rs-fMRI acquisition, the participants were instructed to look at a white cross on a screen, to relax and not to fall asleep. Excessive head movement was prevented by stabilizing the head of the participants with adapted material. Earplugs were used to increase participants' comfort and to relatively reduce scannerinduced auditory system stimulation during the restingstate acquisition.

Preprocessing of Structural and Functional Images

The preprocessing was done using Statistical Parametric Mapping (SPM8, Wellcome Trust Centre for Neuroimaging, London, UK: http://www.fil.ion.ucl.ac.uk/spm/) and Matlab 2011b (http://www.mathworks.com) using the same steps already described in (Richiardi et al. 2012). Functional images were motion corrected and realigned to the mean. There was no significant between-groups difference in the motion parameters. (all $p$ values were above 0.1 uncorrected). The structural images were segmented using the SPM8 New Segment algorithm (Ashburner and Friston 2005), normalized to MNI and the forward and inverse deformation fields were saved. The inverse deformation field was used to warp the AAL atlas (TzourioMazoyer et al. 2002) into each subject space and parcellate the subject's anatomical images in 90 regions of interest (ROIs) with an adapted version of the IBASPM toolbox (Alemán-Gómez and Valdés-Hernandez 2006). Each subject's specific anatomical atlas was then converted to a functional atlas and both images were inspected. Finally, the region-averaged time series were extracted, linearly detrended and the realignment parameters, as well as the signal of the 100 voxels with maximum intensity, representative for white matter, were regressed out. The wavelet transform (orthogonal cubic B-spline wavelets) was used to filter the signal in order to keep the $0.05-0.1 \mathrm{~Hz}$ frequency range (Achard et al. 2006). The globus pallidus bilaterally was not included in the analysis due to a signal drop in several subjects.

\section{Connectivity-Based Classification}

Functional connectivity was computed by calculating the Pearson correlation coefficient between the filtered time series of each pair of regions. Thus we obtained for every subject an $88 \times 88$ matrix in which each element represented the connectivity strength between two regions. For each connection, a linear regression was used to correct the data for age and gender. The matrices were then z-scored in order to reduce inter-subject variability. Finally, we vectorized the upper triangular part of each matrix to obtain feature vectors composed of 3,828 connections that were used for classification (Jonas Richiardi et al. 2010; Richiardi et al. 2012).

Classification and analysis of the discriminative graph were performed the same way for the two groups described in the "Participants" part of the Method section. A linear SVM classifier [LIBSVM (Chang and Lin 2011)] was used for classification the accuracy of which was evaluated using a leave-one-subject-out cross validation loop (LOOCV). We included within the LOOCV a feature selection based on point biserial correlation and tested the accuracy selecting an increasing number of connections going from 5 to 2,000 connections by steps of 5 . The feature selection and the training of the classifier were strictly performed on the training group only in order to avoid double dipping and overestimation of accuracy (Kriegeskorte et al. 2009). Finally, a Wilson's score interval was used to calculate the accuracy $95 \%$ Confidence Interval (CI) around the point estimate of accuracy. The reported accuracies were recomputed while keeping age and gender correction within the LOOCV to estimate the impact of these confounds.

\section{Discriminative Graph Analysis}

We defined our discriminative graph as being a binary graph composed of the minimal $N$ connections that yielded the highest accuracy, as the addition of other connections did not bring more information about the diagnosis. Because the features selected at each iteration of the LOOCV may vary, we restricted our analysis to the connections that were kept for classification at least $80 \%$ of the time, and thus are strongly associated with the diagnosis in our sample.

We first looked at the distribution of connections between the different cerebral lobes, following the division by Tzourio-Mazoyer et al. (2002) and including the insula in the limbic lobe. Each connection's end was counted to ensure that intra- and interlobar connections have equal importance. Then, for each connection present in the discriminative graph, the difference between the mean connectivity in each group was computed in order to know whether the connections were stronger or weaker. We also calculated the degree of the discriminative graph, which is the number of connections present in each ROI.

Finally, to test whether there was a relationship between IQ and dysconnectivity in the comparison between the 22q11DS and control groups, summary indices of connectivity were used, as described by Richiardi et al. (2012). 
Firstly, the weight of each connection was obtained by training the classifier on the whole group using only the discriminative connections. Then, a global connectivity index (GCI) was computed for each subject as being the sum of the discriminant connections multiplied by their weight for classification. We used the normalized matrices because of the high variability in mean connectivity between the subjects. Increased (ICI) and decreased connectivity indices (DCI) were computed the same way, using only the connections that were stronger and weaker, respectively. These indices were then correlated to IQ using a Pearson correlation coefficient and tested for the influence of age and gender using a partial correlation.

\section{Results}

Discrimination Between Patients with 22q11DS and Healthy Controls

\section{Connectivity-Based Classification}

A maximal accuracy of $84 \%$ (CI 75-91\%) was reached using only 45 connections, representing $1.18 \%$ of the total brain network (Fig. 1a), with only two more patients misclassified when correcting for age and gender within the LOOCV. The classifier performed better in excluding 22q11DS ( $88 \%$ specificity, 5 misclassified controls) than in identifying the syndrome ( $81 \%$ sensitivity, 8 misclassified patients). During the LOOCV, 37 connections out of 45 were retained $80 \%$ of the time, whereas 30 were retained at each iteration. The discriminative graph was thus defined as the graph composed of these 37 connections.

\section{Discriminative Graph Analysis}

The discriminative graph's connections were mostly located within the left $(30 \%)$ and right frontal $(26 \%)$ lobes, which corresponds to 1.5 and $1.2 \%$ of the connections in these lobes, respectively. The right temporal lobe has also high relative importance, as $1.8 \%$ of its connections were retained. The distribution of the connections across all lobes is further detailed in Fig. 1b, and the amount of retained connections per lobe is shown in Fig. 1c. The connections kept $90 \%$ of the time showed a similar distribution, but when considering the connections retained at all folds of the LOOCV, only $0.8 \%$ of the right frontal lobe connections remained in the discriminative graph, whereas the rest of the distribution was similar. The proportion of connections that were either stronger or weaker in the 22q11DS group was equivalent (49 and 51\%

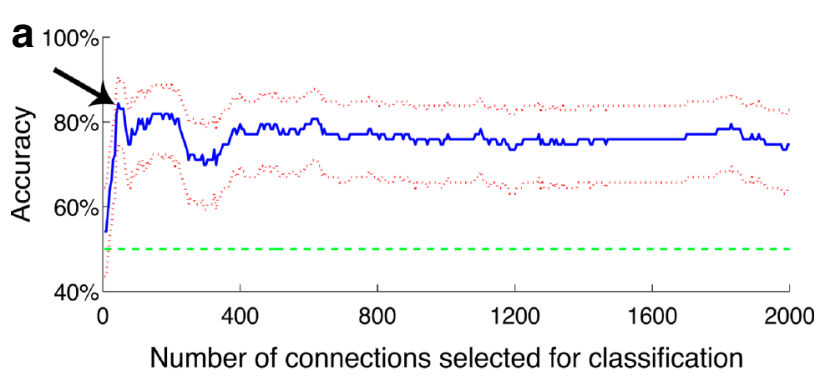

b
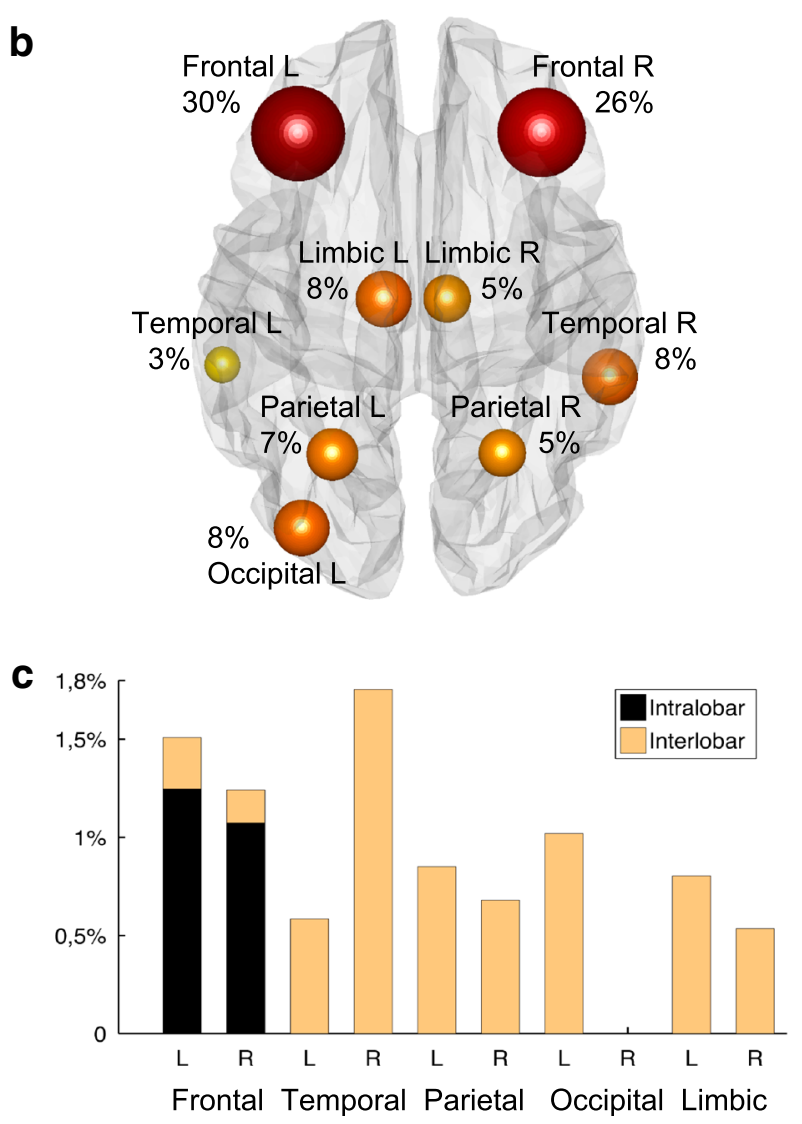

Fig. 1 Differentiation between patients with 22q11DS and healthy controls. a Accuracy of the classifier plotted against the number of connections retained for classification (filled line), upper and lower $95 \%$ confidence interval are plotted in dotted lines, significance level is shown at $50 \%$ accuracy (dotted line). Maximal peak of accuracy is indicated by an arrow and corresponds to an $84 \%$ of correct identification of the patients versus the healthy controls achieved with 45 connections. $\mathbf{b}, \mathbf{c}$ Analysis of the discriminative graph at maximal accuracy: $\mathbf{b}$ distribution of the connections across the lobes. The size and color of the spheres are proportional to the number of connections retained in each lobe. $\mathbf{c}$ Amount of connections retained in each lobe. The proportion of intralobar connections (i.e. the connections that remain in the lobe) and interlobar connections (that connect the lobe with any other lobe) are shown (Color figure online)

respectively). However, intralobar connections were mostly stronger in the patients group $(70 \%)$ whereas interlobar connections were weaker $(59 \%)$. 

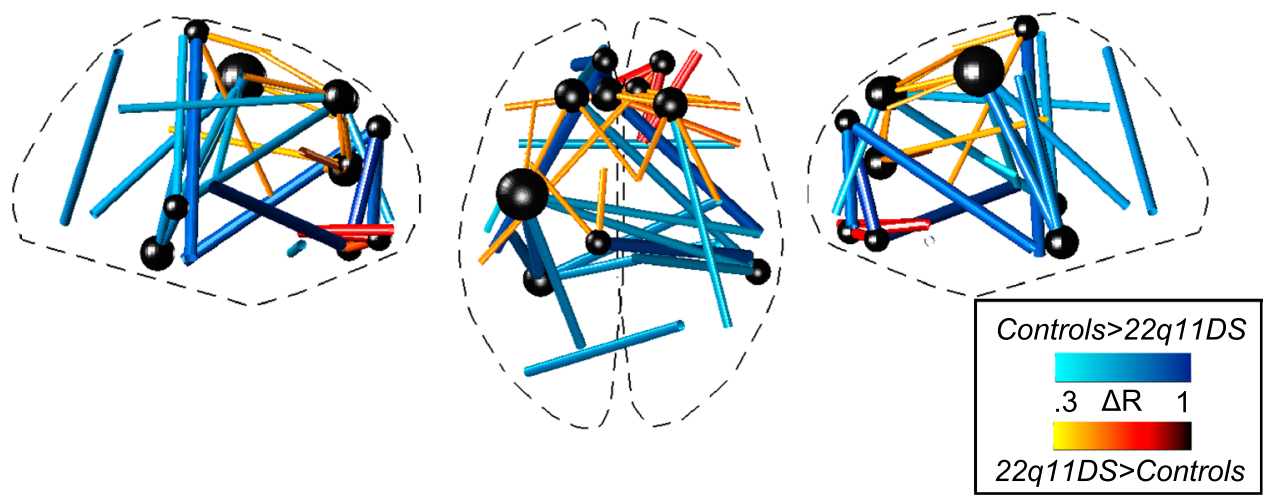

Fig. 2 Brain map showing the discriminative connections for the differentiation between patients with $22 \mathrm{q} 11.2$ deletion syndrome (22q11DS) versus healthy controls at maximal accuracy. The thickness of the connections is proportional to the difference of mean connectivity between the groups $(\Delta \mathrm{R})$. The connections that are

The regions with a high degree were located mostly within the frontal lobes. For instance, eleven regions had a degree higher than 1.5 standard deviations above the mean degree of the discriminative graph: anterior cingulate and superior frontal gyri bilaterally, left precentral, medial frontal, rectus, paracentral and fusiform gyri and right middle temporal and orbitofrontal gyri (Fig. 2).

Finally, we found a positive correlation between GCI and full scale IQ (FSIQ) in the patients group $(r=0.42$, $N=41, p=0.007$ ) (Fig. 3). The connections that were weaker in patients had more influence on the correlation as FSIQ correlated stronger with DCI $(r=0.32, N=41$, $p=0.041)$ than with ICI $(r=0.2, N=41, p=0.16)$. These results remained significant when taking age and gender into account. The correlation between GCI and FSIQ was the only one to sustain correction for multiple comparisons [false discovery rate (Benjamini 1995)].

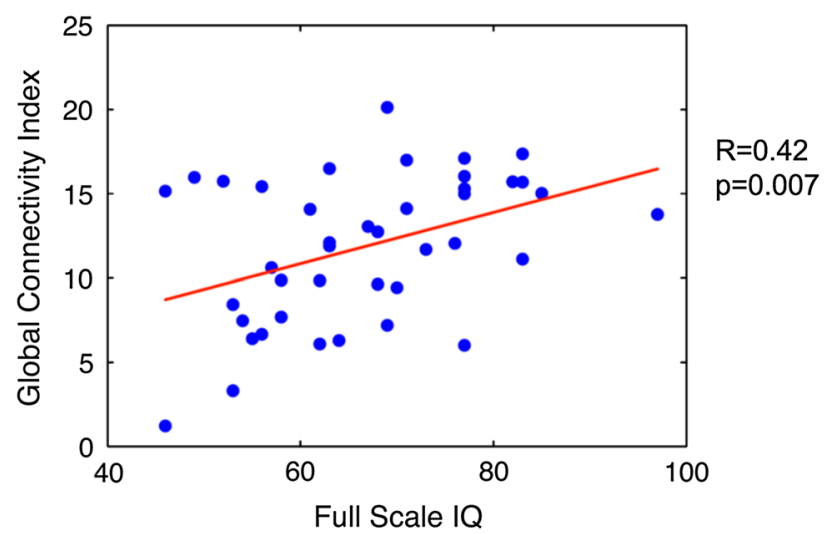

Fig. 3 Scatterplot and correlation between Full Scale IQ and Global Connectivity Index in the 22q11DS group weaker in 22q11DS are in blue scale, stronger are in red scale. The spheres show the brain regions that have a degree higher than 1.5 standard deviations above the mean, the size of the sphere being proportional to the degree (Color figure online)

Identification of Moderate to Severe Psychotic Symptoms Within the Patients Group

\section{Connectivity-Based Classification}

For the classification of the PS+ versus the PS - groups, the classifier reached a maximal accuracy of $88 \%$ (CI 71-96\%), significantly above chance while keeping 65 connections. This accuracy corresponds to a specificity of $92 \%$ and a sensitivity of $84 \%$. All patients included only in the testing group were correctly classified. Correction for age and gender within the LOOCV led to two more misclassifications (non-significant difference). Among the discriminant connections, 42 were selected in the LOOCV $80 \%$ of the time and composed our discriminative graph. From these connections, 38 were kept each time. None of these connections was part of the discriminative graph retained for discrimination between patients and controls, showing that the classifier identified different networks for each classification.

\section{Discriminative Graph Analysis}

Most discriminative connections were located in the frontal lobes (left: $26 \%$, right: $27 \%$ ), corresponding to 1.4 and $1.5 \%$ of the connections of these lobes, respectively. Several other lobes also had high relative importance; i.e. $1.2 \%$ of left temporal, $1 \%$ of left and right parietal and left limbic connections were retained for classification. There was no major difference in the distribution when considering only the connections selected in 90 or $100 \%$ of the folds of the LOOCV. The discriminative connections were more often stronger $(62 \%)$ in the PS+ group compared to the PSgroup mostly in bilateral parietal and left temporal lobe (Fig. 4a). By contrast, all the connections of the limbic lobes 


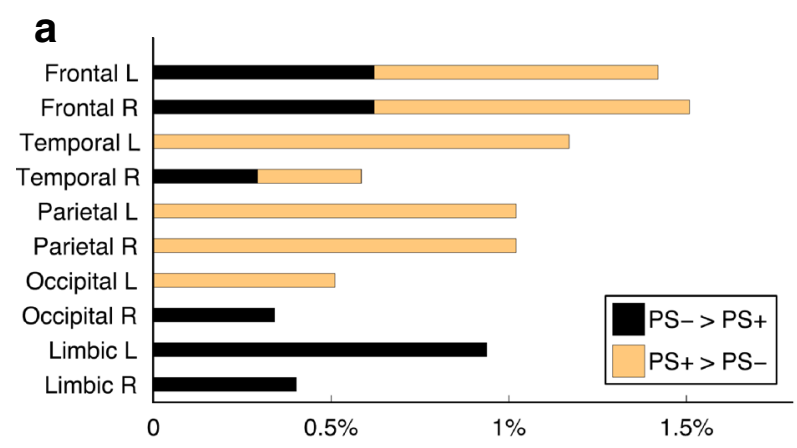

b

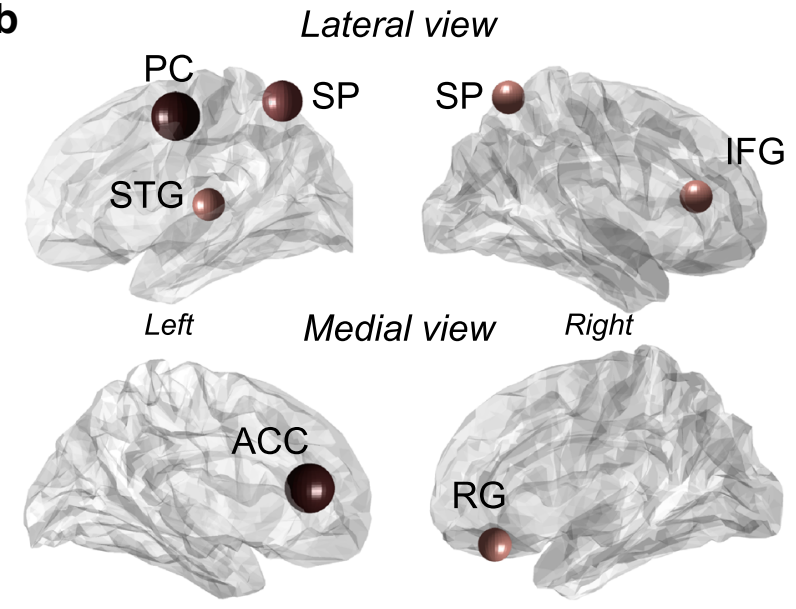

Fig. 4 Differentiation between patients that suffer of mild to severe positive psychotic symptoms and the rest of the patients' group. a Plot showing the proportion of connections present for each lobe in the discriminative graph at maximal accuracy. The proportion of connections that were weaker or stronger in patients that suffered of psychotic symptoms compared to the rest of the patients are displayed. b Brain maps showing the regions that have a degree superior than 1.5 standard deviations above the mean in the discriminative graph. The size and color of the spheres are proportional to the degree. $L$ left, $R$ right, $P S+$ patients with psychotic symptoms, $P S-$ patients without psychotic symptoms, $A C C$ anterior cingulate cortex; $I F G$ inferior frontal gyrus (pars triangularis); $P C$ precentral gyrus; $R G$ rectus gyrus; $S P$ superior parietal gyrus (Color figure online)

were weaker in the PS+ group. The ROIs with the highest discriminative degree were the left anterior cingulate, left precentral, right pars triangularis, left superior temporal, bilateral superior parietal and right rectus gyri (Fig. 4b).

\section{Discussion}

In the present study, we investigated functional brain networks at rest in patients with a 22q11DS using a connectivity decoding approach. The SVM classifier performed significantly above chance in differentiating patients with 22q11DS from healthy controls, and in identifying the patients suffering from mild to severe psychotic symptoms within the 22q11DS group. These results provide evidence for widespread alterations of functional connectivity in 22q11DS and for relationships between functional dysconnectivity at rest and psychosis within the patients group.

\section{Discriminating Patients with 22q11DS from Healthy Controls}

The classifier achieved high accuracy in detecting the 22q11DS condition, using only $1.3 \%$ of the network connections. Although these discriminative connections were widespread, functional connectivity of the frontal lobe played an important role in classification. Several studies using DTI have already identified a widespread alteration of the structural brain network in 22q11DS (Barnea-Goraly et al. 2003; Simon et al. 2005; Sundram et al. 2010; Radoeva et al. 2012) that also affect tracts originating from the frontal lobe (Simon et al. 2008; Barnea-Goraly et al. 2003; Radoeva et al. 2012). This has been further confirmed by a recent tractographic study showing alterations in the number of reconstructed fibers in several brain lobes, including the frontal lobes (Ottet et al. 2013a). However, contrarily to our results that indicate a dysfunction predominantly located within the frontal lobes, morphometric studies usually describe a relative preservation of the frontal volume in the syndrome (Eliez et al. 2000; Kates et al. 2001, 2004; Simon et al. 2005). Nevertheless, localized frontal gray matter alterations have also been described (Shashi et al. 2010; van Amelsvoort et al. 2001; Schaer et al. 2009; Bearden et al. 2007) notably in regions that have a high degree in our discriminative graph, such as superior, medial (Schaer et al. 2009), and orbital (Bearden et al. 2007) frontal regions. These morphological alterations could be related to the underlying disruption of the structural network (He et al. 2007; Lerch et al. 2006; Alexander-Bloch et al. 2013) and could also affect the function of the frontal lobe and its interactions with the rest of the brain. However, brain structure-function relationships are highly complex as functional networks vary in a much shorter time-scale than structural networks and are highly dependent on external stimuli or on the performed task (Bullmore and Sporns 2009). Furthermore, function does not only reflect underlying structural alterations but can also be the result of an adaptation to a different structural background. Such complex relationships could explain why we observe only few discriminative connections in the functional network of the parietal lobe whereas structural alterations are consistently reported in this region (Antshel et al. 2008b; Gothelf et al. 2008). Investigation of brain connectivity with multimodal neuroimaging approaches, task-related fMRI or dynamic measurements of connectivity will be necessary to provide new 
understanding of how the structural and functional alterations described in 22q11DS are related together.

In a previous rs-fMRI study, we identified DMN alterations located within the left superior and medial frontal gyri in youths with 22q11DS (Debbane et al. 2012). These same regions were also amongst the ROIs showing the highest degree in the present study. Although the two studies share part of their samples, we interpret this finding as being a robust evidence for left superior and medial frontal functional alterations at rest in $22 q 11 D S$, as it is confirmed by different analysis methods and age ranges. We did not replicate, however, the differences in high-level and visuo-spatial processing networks that we previously identified. These differences between the two studies may be related to the different methods used to define the brain networks that uncover different aspects of functional brain connectivity. As our previous study only included adolescents these differences could also represent functional connectivity alterations specific to this time period. Indeed, the precuneus, a central structure in the adult connectome (van den Heuvel and Sporns 2011), has also been shown to be one of the brain regions in which connectivity is the most age predictive (Dosenbach et al. 2010). Furthermore, impaired development of resting-state connectivity in 22q11DS has recently been described by another group on an independent sample of patients (Schreiner et al. 2013). Even though the authors only examined the connectivity of the posterior cingulate cortex, it is likely that a similar pattern may be identified in other brain regions. Therefore, the differences we identified only in the adolescent group could be related to a delayed maturation of the functional brain network in the 22q11DS and should be further investigated. Finally, we found evidence for dysconnectivity in the right middle temporal gyrus only in the present study. This region is usually considered to be part of the social network and to respond to the emotional content of language (Wildgruber et al. 2006), body (Van Overwalle and Baetens 2009) or faces (Haxby et al. 2000). Even though an alteration of the social network has been hypothesized in the 22q11DS (Baker and Skuse 2005; Baker and Vorstman 2012), evidence for a dysfunction located in the temporal lobe has not been consistently reported in the literature (Andersson et al. 2008; van Amelsvoort et al. 2006) and needs to be further investigated.

As expected, the set of discriminative connections was correlated to the difference in IQ between our groups, particularly when considering the DCI. Frontal regions are important integrative areas that support functions such as working memory, judgment (Opris and Bruce 2005; Volz et al. 2006) or planning (Brancucci 2012; Sun and Buys 2012). These integrative functions are thought to depend on the frontal network configuration and its ability to allow locally specialized processing of information as well as synchronization between distant regions (Sporns et al. 2005; Brancucci 2012). Thus the alteration of the frontal network and the decreased interlobar functional connectivity we identified in 22 q11DS could correspond to an alteration of the brain's integrative capacities, impacting the cognitive abilities of the patients. Indeed, a few studies have already reported a relationship between IQ and measures of brain networks integration (van den Heuvel et al. 2009; Li et al. 2009). Graph theoretical analysis of brain connectivity in 22 q11DS could confirm this hypothesis as it provides quantitative measures of integration and segregation of the networks (Bullmore and Sporns 2009).

Identification of Patients with Psychotic Symptoms Within the 22q11DS Group

The classifier accurately identified the patients with 22q11DS suffering from mild to severe psychotic symptoms by showing specific functional connectivity alterations related to the development of early psychosis. As no connections were retained for both classifications, these results suggest that functional dysconnectivity related to the presence of cognitive deficits may be different from the dysconnectivity responsible for the development of psychosis in this population. However, we strictly kept only the most discriminant features in order to identify the major differences between the groups, so it is not excluded that defining the discriminative connections less strictly could have revealed some overlap between the two comparisons.

Our results show that functional brain connectivity alterations can be identified before the development of full blown psychosis in 22q11DS and involve regions already known to be affected in schizophrenia and in its prodromal phase (Jung et al. 2010), such as ACC, right inferior frontal (Pettersson-Yeo et al. 2011; Vercammen et al. 2010) or left superior temporal cortex (Honea et al. 2005; Allen et al. 2007). For instance, early impairment of frontal and temporal connectivity has been described in other populations with a prodromal psychotic syndrome (Pettersson-Yeo et al. 2011; Jung et al. 2010). DTI studies have shown a decrease in FA in the superior longitudinal fasciculus, which connects frontal, temporal and parietal lobes, both in patients with a first-episode psychosis (Luck et al. 2011) and in patients with Ultra High Risk (Yung et al. 2008; Fusar-Poli et al. 2013) characteristics (Karlsgodt et al. 2009). Similarly functional fronto-temporal (Crossley et al. 2009), fronto-parietal (Schmidt et al. 2013) and frontostriatal (Fornito et al. 2013) dysconnectivity have been described in the same prodromal syndromes. Our results partially overlap with the brain networks alterations described in prodromal populations suggesting that common mechanisms underlie the development of psychosis in $22 q 11 D S$ and in the general population. Even though we 
did not identify cortico-subcortical dysconnectivity, we found predominant frontal and left temporal dysconnectivity and an involvement bilateral superior parietal lobe in classification (Fig. 4). Fronto-temporal white matter tracts alterations (Ottet et al. 2013a; Barnea-Goraly et al. 2003) and their relationship with psychotic symptoms (da Silva et al. 2011; Ottet et al. 2013b) in the 22q11DS population further sustain this hypothesis.

Apart from the frontal and temporal dysconnectivity, we found that the ACC is one of the two brain regions that has the most important number of discriminative connections and therefore plays an important role in identifying the patients that suffer from psychotic symptoms. In the literature, the ACC is described as a core node in the pathogenesis of psychosis. Indeed decreased ACC volume (Jung et al. 2010), as well as structural (Pettersson-Yeo et al. 2011) and functional (Lord et al. 2011; Allen et al. 2010; Pettersson-Yeo et al. 2011) ACC dysconnectivity have been identified prior to the onset of schizophrenia. This region has been associated with deficits in executive functions in schizophrenia (Minzenberg et al. 2009), and it is supposed to play a role in the generation of auditory-verbal hallucinations in association with the left superior temporal and language-related regions (Allen et al. 2007). Indeed, ACC dysconnectivity could be related to wrong monitoring of self-relevant stimuli and misattribution of thoughts to external sources (Murray et al. 2012; Vercammen et al. 2010). A recent model postulates that the salience network, composed of ACC and anterior insula, prevents the appropriate switch of attention between internal self-referential thinking and external attention to relevant stimuli in schizophrenia (Menon 2011). This hypothesis is further sustained by several reports showing an altered pattern of deactivation of the DMN during a task in schizophrenic patients (Garrity et al. 2007) and in populations at genetic (Whitfield-Gabrieli et al. 2009; Karbasforoushan and Woodward 2012) or clinical risk for psychosis (Shim et al. 2010; Fryer et al. 2013). Finally, a role of the ACC in mediating fronto-temporal connectivity and inducing compensatory mechanisms has also been hypothesized in the schizophrenic prodrome. (Allen et al. 2010). In 22q11DS too, alterations of the ACC have been identified both at structural (Bearden et al. 2009; Schaer et al. 2010) and functional levels. In particular, a dysfunction of this region has been described in an auditory gating task (Rihs et al. 2012) and a self-reflecting task (Schneider et al. 2012). ACC activity in the latter was furthermore correlated with the severity of the prodromal psychotic symptoms. However, it is still not clear whether these alterations progressively appear within the course of illness of if they precede and represent a potential vulnerability marker for schizophrenia.

In this context, pattern recognition approaches raise the hope of providing new diagnostic tools for psychiatry that could help identify at-risk patients, evaluate their prognosis and target treatment. Indeed, machine-learning methods have the advantage of detecting complex patterns of features associated with a condition and allowing inference at an individual level (Orru et al. 2012). Structural neuroimaging has already been successfully used to identify patients with schizophrenia (Davatzikos et al. 2005) and atrisk mental states (Koutsouleris et al. 2009, 2010; Borgwardt et al. 2013) from healthy controls. Brain function may also be a sensitive marker as response to an emotional processing paradigm successfully revealed psychosis proneness in the general population (Modinos et al. 2012, 2013). Here, we show that whole-brain resting-state connectivity is another promising biomarker to identify the presence of mild to severe psychotic symptoms. However, only longitudinal studies will determine if such dysconnectivity can predict clinical outcome in patients. Good prediction rates have been obtained for instance with structural neuroimaging in patients with a prodromal syndrome (Mourao-Miranda et al. 2012; Koutsouleris et al. 2009, 2010; Borgwardt et al. 2013) and in 22q11DS (Gothelf et al. 2011). However, evidence is still lacking for other neuroimaging features. Several authors have now suggested to aim for a two steps approach in the management of at-risk patients by adding a classification step after their clinical identification (Koutsouleris et al. 2012; Ruhrmann et al. 2010). The proposed classifications may use clinical, cognitive, environmental and neuroimaging features alone or in combination (Shah et al. 2012). This should allow to more closely identify which patients have a higher risk develop a first-episode psychosis among the prodromal population and to provide more targeted treatment.

\section{Conclusion and Limitations}

In this study, we provide evidence for altered frontal and right temporal brain connectivity at rest in 22q11DS related to intellectual impairment. We showed that the presence of mild to severe psychotic symptoms is associated with resting-state networks alterations affecting mainly left ACC, superior temporal gyrus and right VLPFC. Such early dysconnectivity provides a promising biomarker for psychosis. Given the low prevalence of the 22q11DS in the general population, the number of patients included in this study is relatively low, warranting further replication. Therefore, several limitations can be identified. First, we were not able to test for potential difference in the effect of age on brain connectivity between the groups and used a linear regression to remove the noise introduced by the large age-range of our sample. A residual effect of age may therefore remain in our results. Furthermore because of the cognitive deficits of the patients, motion is another 
particular issue when studying this population. We took the following steps to address this issue: we carefully excluded the subjects with head motion using a strict threshold of $3 \mathrm{~mm}$; we regressed the motion artifacts from our data; and we excluded the presence of any significant between-group difference in the motion regressors. However, despite all these efforts, we cannot exclude the fact that some of our results may be related to a residual effect of motion. Several research groups are currently looking for optimal denoising methods (Satterthwaite et al. 2013; Power et al. 2012; Van Dijk et al. 2012; Tohka et al. 2008) in rs-fMRI, but it is still unknown if one method is better than the others. Specifically we chose not to use motion scrubbing (Power et al. 2012; Van Dijk et al. 2012), as the impact of frames removal and disruption of the temporal structure of the data is controversial when studying populations where the amount of frames to remove is not negligible (Satterthwaite et al. 2013). Indeed, it may introduce signal and statistical power loss and bias the results. In this context, other denoising methods such as ICA artifacts regression (Tohka et al. 2008) or wavelet despiking (Mazaika et al. 2009) might be superior, but this remains to be established. Finally, we cannot exclude a bias introduced by medication or by differences in the subject's learning profile (for instance bilingualism) related to the cognitive difficulties associated with the 22q11DS.

Acknowledgements We would like to thank Ayca Karagöz Uzel, Laure Chevalley and Elodie Cuche for participating in data collection; Sophie Dahoun, Christine Hinard and Lucia Bartoloni for genetical analyses and Sarah Menghetti for her involvement with the families and proofreading the manuscript. Further thanks go to François Lazeyras, Frank Henry and Yohann Ouvrier Buffet at the CIBM. Finally we acknowledge the patients and their families who kindly participated in our study. This study was supported by the Swiss National Science Foundation (SNF) (Grant numbers: to S. Eliez 32473B_121996 and 234730_144260; to D. Van De Ville PP00P2_123438 and PP00P2_123438) and by the National Center of Competence in Research (NCCR) "Synapsy-The Synaptic Bases of Mental Diseases" (SNF, Grant number: 51AU40_125759). E. Scariati (\#145250) and M. Schaer (\#145760) were supported by a fellowship from the SNF and J. Richiardi by a Marie-Curie International Outgoing Fellowship (\#299500).

Conflict of interest The authors declare no conflicts of interest.

\section{References}

Achard S, Salvador R, Whitcher B, Suckling J, Bullmore E (2006) A resilient, low-frequency, small-world human brain functional network with highly connected association cortical hubs. J Neurosci 26(1):63-72. doi:10.1523/JNEUROSCI.3874-05.2006

Alemán-Gómez YM-GL, Valdés-Hernandez P (2006) IBASPM: toolbox for automatic parcellation of brain structures. In: Paper presented at the presented at the 12th annual meeting of the organization for human brain mapping, Florence, Italy, June $11-15$
Alexander-Bloch A, Giedd JN, Bullmore E (2013) Imaging structural co-variance between human brain regions. Nat Rev Neurosci. doi: $10.1038 / \mathrm{nrn} 3465$

Allen P, Aleman A, McGuire PK (2007) Inner speech models of auditory verbal hallucinations: evidence from behavioural and neuroimaging studies. Int Rev Psychiatry 19(4):407-415. doi:10. 1080/09540260701486498

Allen P, Stephan KE, Mechelli A, Day F, Ward N, Dalton J, Williams SC, McGuire P (2010) Cingulate activity and fronto-temporal connectivity in people with prodromal signs of psychosis. Neuroimage 49(1):947-955. doi:10.1016/j.neuroimage.2009.08. 038

Andersson F, Glaser B, Spiridon M, Debbane M, Vuilleumier P, Eliez $S$ (2008) Impaired activation of face processing networks revealed by functional magnetic resonance imaging in $22 \mathrm{q} 11.2$ deletion syndrome. Biol Psychiatry 63(1):49-57. doi:10.1016/j. biopsych.2007.02.022

Antshel KM, Fremont W, Kates WR (2008a) The neurocognitive phenotype in velo-cardio-facial syndrome: a developmental perspective. Dev Disabil Res Rev 14(1):43-51. doi:10.1002/ddrr.7

Antshel KM, Peebles J, AbdulSabur N, Higgins AM, Roizen N, Shprintzen R, Fremont WP, Nastasi R, Kates WR (2008b) Associations between performance on the rey-osterrieth complex figure and regional brain volumes in children with and without velocardiofacial syndrome. Dev Neuropsychol 33(5):601-622. doi:10.1080/87565640802254422

Ashburner J, Friston KJ (2005) Unified segmentation. Neuroimage 26(3):839-851. doi:10.1016/j.neuroimage.2005.02.018

Baker KD, Skuse DH (2005) Adolescents and young adults with 22q11 deletion syndrome: psychopathology in an at-risk group. Br J Psychiatry 186:115-120. doi:10.1192/bjp.186.2.115

Baker K, Vorstman JA (2012) Is there a core neuropsychiatric phenotype in 22q11.2 deletion syndrome? Curr Opin Neurol 25(2):131-137. doi:10.1097/WCO.0b013e328352dd58

Barnea-Goraly N, Menon V, Krasnow B, Ko A, Reiss A, Eliez S (2003) Investigation of white matter structure in velocardiofacial syndrome: a diffusion tensor imaging study. Am J Psychiatry 160(10): 1863-1869

Barnea-Goraly N, Eliez S, Menon V, Bammer R, Reiss AL (2005) Arithmetic ability and parietal alterations: a diffusion tensor imaging study in velocardiofacial syndrome. Brain Res Cogn Brain Res 25(3):735-740. doi:10.1016/j.cogbrainres.2005.09. 013

Bassett DS, Nelson BG, Mueller BA, Camchong J, Lim KO (2012) Altered resting state complexity in schizophrenia. Neuroimage 59(3):2196-2207. doi:10.1016/j.neuroimage.2011.10.002

Bearden CE, van Erp TG, Dutton RA, Tran H, Zimmermann L, Sun D, Geaga JA, Simon TJ, Glahn DC, Cannon TD, Emanuel BS, Toga AW, Thompson PM (2007) Mapping cortical thickness in children with 22q11.2 deletions. Cereb Cortex 17(8):1889-1898. doi:10.1093/cercor/bhl097

Bearden CE, van Erp TG, Dutton RA, Lee AD, Simon TJ, Cannon TD, Emanuel BS, McDonald-McGinn D, Zackai EH, Thompson PM (2009) Alterations in midline cortical thickness and gyrification patterns mapped in children with 22q11.2 deletions. Cereb Cortex 19(1):115-126. doi:10.1093/cercor/bhn064

Benjamini YHY (1995) Controlling the false discovery rate: a practical and powerful approach to multiple testing. J R Stat Soc 57(1):289-300

Borgwardt S, Koutsouleris N, Aston J, Studerus E, Smieskova R, Riecher-Rossler A, Meisenzahl EM (2013) Distinguishing prodromal from first-episode psychosis using neuroanatomical single-subject pattern recognition. Schizophr Bull 39(5): 1105-1114. doi:10.1093/schbul/sbs095

Brancucci A (2012) Neural correlates of cognitive ability. J Neurosci Res 90(7):1299-1309. doi:10.1002/jnr.23045 
Buckholtz JW, Meyer-Lindenberg A (2012) Psychopathology and the human connectome: toward a transdiagnostic model of risk for mental illness. Neuron 74(6):990-1004. doi:10.1016/j.neuron. 2012.06.002

Bullmore E, Sporns O (2009) Complex brain networks: graph theoretical analysis of structural and functional systems. Nat Rev Neurosci 10(3):186-198. doi:10.1038/nrn2575

Chang CC, Lin CJ (2011) LIBSVM: a library for support vector machines. ACM Trans Intel Syst Technol 2(3):1-27. doi:10. 1145/1961189.1961199

Cole MW, Yarkoni T, Repovs G, Anticevic A, Braver TS (2012) Global connectivity of prefrontal cortex predicts cognitive control and intelligence. J Neurosci 32(26):8988-8999. doi:10. 1523/JNEUROSCI.0536-12.2012

Craddock RC, Holtzheimer PE 3rd, Hu XP, Mayberg HS (2009) Disease state prediction from resting state functional connectivity. Magn Reson Med 62(6):1619-1628. doi:10.1002/mrm.22159

Crossley NA, Mechelli A, Fusar-Poli P, Broome MR, Matthiasson P, Johns LC, Bramon E, Valmaggia L, Williams SC, McGuire PK (2009) Superior temporal lobe dysfunction and frontotemporal dysconnectivity in subjects at risk of psychosis and in firstepisode psychosis. Hum Brain Mapp 30(12):4129-4137. doi:10. 1002/hbm.20834

da Silva Alves F, Schmitz N, Bloemen O, van der Meer J, Meijer J, Boot E, Nederveen A, de Haan L, Linszen D, van Amelsvoort T (2011) White matter abnormalities in adults with 22q11 deletion syndrome with and without schizophrenia. Schizophr Res 132(1):75-83. doi:10.1016/j.schres.2011.07.017

Davatzikos C, Shen D, Gur RC, Wu X, Liu D, Fan Y, Hughett P, Turetsky BI, Gur RE (2005) Whole-brain morphometric study of schizophrenia revealing a spatially complex set of focal abnormalities. Arch Gen Psychiatry 62(11):1218-1227. doi:10.1001/ archpsyc.62.11.1218

Debbane M, Lazouret M, Lagioia A, Schneider M, Van De Ville D, Eliez S (2012) Resting-state networks in adolescents with 22q11.2 deletion syndrome: associations with prodromal symptoms and executive functions. Schizophr Res 139(1-3):33-39. doi:10.1016/j.schres.2012.05.021

Dosenbach NU, Nardos B, Cohen AL, Fair DA, Power JD, Church JA, Nelson SM, Wig GS, Vogel AC, Lessov-Schlaggar CN, Barnes KA, Dubis JW, Feczko E, Coalson RS, Pruett JR Jr, Barch DM, Petersen SE, Schlaggar BL (2010) Prediction of individual brain maturity using fMRI. Science 329(5997): 1358-1361. doi:10.1126/science.1194144

Eliez S, Schmitt JE, White CD, Reiss AL (2000) Children and adolescents with velocardiofacial syndrome: a volumetric MRI study. Am J Psychiatry 157(3):409-415

Filippi M, Agosta F (2011) Structural and functional network connectivity breakdown in Alzheimer's disease studied with magnetic resonance imaging techniques. J Alzheimers Dis 24(3): 455-474. doi:10.3233/JAD-2011-101854

First MB (1997) Structured clinical interview for DSM-IV axis II personality disorders: SCID-II. American Psychiatric Press, Washington

Fornito A, Harrison BJ, Goodby E, Dean A, Ooi C, Nathan PJ, Lennox BR, Jones PB, Suckling J, Bullmore ET (2013) Functional dysconnectivity of corticostriatal circuitry as a risk phenotype for psychosis. JAMA Psychiatry 70(11):1143-1151. doi:10.1001/jamapsychiatry.2013.1976

Fox MD, Raichle ME (2007) Spontaneous fluctuations in brain activity observed with functional magnetic resonance imaging. Nat Rev Neurosci 8(9):700-711. doi:10.1038/nrn2201

Fryer SL, Woods SW, Kiehl KA, Calhoun VD, Pearlson GD, Roach BJ, Ford JM, Srihari VH, McGlashan TH, Mathalon DH (2013) Deficient suppression of default mode regions during working memory in individuals with early psychosis and at clinical high- risk for psychosis. Front Psychiatry 4:92. doi:10.3389/fpsyt. 2013.00092

Fusar-Poli P, Borgwardt S, Bechdolf A, Addington J, Riecher-Rossler A, Schultze-Lutter F, Keshavan M, Wood S, Ruhrmann S, Seidman LJ, Valmaggia L, Cannon T, Velthorst E, De Haan L, Cornblatt B, Bonoldi I, Birchwood M, McGlashan T, Carpenter W, McGorry P, Klosterkotter J, McGuire P, Yung A (2013) The psychosis high-risk state: a comprehensive state-of-the-art review. JAMA Psychiatry 70(1):107-120. doi:10.1001/jamapsy chiatry.2013.269

Garrity AG, Pearlson GD, McKiernan K, Lloyd D, Kiehl KA, Calhoun VD (2007) Aberrant "default mode" functional connectivity in schizophrenia. Am J Psychiatry 164(3): 450-457. doi:10.1176/appi.ajp.164.3.450

Gothelf D, Schaer M, Eliez S (2008) Genes, brain development and psychiatric phenotypes in velo-cardio-facial syndrome. Dev Disabil Res Rev 14(1):59-68. doi:10.1002/ddrr.9

Gothelf D, Hoeft F, Ueno T, Sugiura L, Lee AD, Thompson P, Reiss AL (2011) Developmental changes in multivariate neuroanatomical patterns that predict risk for psychosis in 22q11.2 deletion syndrome. J Psychiatr Res 45(3):322-331. doi:10.1016/ j.jpsychires.2010.07.008

Greicius M (2008) Resting-state functional connectivity in neuropsychiatric disorders. Curr Opin Neurol 21(4):424-430. doi:10. 1097/WCO.0b013e328306f2c5

Haxby JV, Hoffman EA, Gobbini MI (2000) The distributed human neural system for face perception. Trends Cogn Sci 4(6): 223-233

He Y, Chen ZJ, Evans AC (2007) Small-world anatomical networks in the human brain revealed by cortical thickness from MRI. Cereb Cortex 17(10):2407-2419. doi:10.1093/cercor/bhl149

Honea R, Crow TJ, Passingham D, Mackay CE (2005) Regional deficits in brain volume in schizophrenia: a meta-analysis of voxel-based morphometry studies. Am J Psychiatry 162(12): 2233-2245. doi:10.1176/appi.ajp.162.12.2233

Jung WH, Jang JH, Byun MS, An SK, Kwon JS (2010) Structural brain alterations in individuals at ultra-high risk for psychosis: a review of magnetic resonance imaging studies and future directions. J Korean Med Sci 25(12):1700-1709. doi:10.3346/ jkms.2010.25.12.1700

Karbasforoushan H, Woodward ND (2012) Resting-state networks in schizophrenia. Curr Top Med Chem 12(21):2404-2414

Karlsgodt KH, Niendam TA, Bearden CE, Cannon TD (2009) White matter integrity and prediction of social and role functioning in subjects at ultra-high risk for psychosis. Biol Psychiatry 66(6):562-569. doi:10.1016/j.biopsych.2009.03.013

Kates WR, Burnette CP, Jabs EW, Rutberg J, Murphy AM, Grados M, Geraghty M, Kaufmann WE, Pearlson GD (2001) Regional cortical white matter reductions in velocardiofacial syndrome: a volumetric MRI analysis. Biol Psychiatry 49(8):677-684

Kates WR, Burnette CP, Bessette BA, Folley BS, Strunge L, Jabs EW, Pearlson GD (2004) Frontal and caudate alterations in velocardiofacial syndrome (deletion at chromosome 22q11.2). J Child Neurol 19(5):337-342

Koutsouleris N, Meisenzahl EM, Davatzikos C, Bottlender R, Frodl T, Scheuerecker J, Schmitt G, Zetzsche T, Decker P, Reiser M, Moller HJ, Gaser C (2009) Use of neuroanatomical pattern classification to identify subjects in at-risk mental states of psychosis and predict disease transition. Arch Gen Psychiatry 66(7):700-712. doi:10.1001/archgenpsychiatry.2009.62

Koutsouleris N, Gaser C, Bottlender R, Davatzikos C, Decker P, Jager M, Schmitt G, Reiser M, Moller HJ, Meisenzahl EM (2010) Use of neuroanatomical pattern regression to predict the structural brain dynamics of vulnerability and transition to psychosis. Schizophr Res 123(2-3):175-187. doi:10.1016/j.schres.2010.08. 032 
Koutsouleris N, Borgwardt S, Meisenzahl EM, Bottlender R, Moller HJ, Riecher-Rossler A (2012) Disease prediction in the at-risk mental state for psychosis using neuroanatomical biomarkers: results from the FePsy study. Schizophr Bull 38(6):1234-1246. doi:10.1093/schbul/sbr145

Kriegeskorte N, Simmons WK, Bellgowan PS, Baker CI (2009) Circular analysis in systems neuroscience: the dangers of double dipping. Nat Neurosci 12(5):535-540. doi:10.1038/nn.2303

Lerch JP, Worsley K, Shaw WP, Greenstein DK, Lenroot RK, Giedd J, Evans AC (2006) Mapping anatomical correlations across cerebral cortex (MACACC) using cortical thickness from MRI. Neuroimage 31(3):993-1003. doi:10.1016/j.neuroimage.2006.01.042

Li Y, Liu Y, Li J, Qin W, Li K, Yu C, Jiang T (2009) Brain anatomical network and intelligence. PLoS Comput Biol 5(5):e1000395. doi:10.1371/journal.pcbi.1000395

Lindsay EA, Goldberg R, Jurecic V, Morrow B, Carlson C, Kucherlapati RS, Shprintzen RJ, Baldini A (1995) Velo-cardiofacial syndrome: frequency and extent of 22q11 deletions. Am J Med Genet 57(3):514-522. doi:10.1002/ajmg.1320570339

Lord LD, Allen P, Expert P, Howes O, Lambiotte R, McGuire P, Bose SK, Hyde S, Turkheimer FE (2011) Characterization of the anterior cingulate's role in the at-risk mental state using graph theory. Neuroimage 56(3):1531-1539. doi:10.1016/j.neuro image.2011.02.012

Luck D, Buchy L, Czechowska Y, Bodnar M, Pike GB, Campbell JS, Achim A, Malla A, Joober R, Lepage M (2011) Fronto-temporal disconnectivity and clinical short-term outcome in first episode psychosis: a DTI-tractography study. J Psychiatr Res 45(3):369-377. doi:10.1016/j.jpsychires.2010.07.007

Mazaika PHF, Glover GH, Reiss AL (2009) Methods and software for fMRI analysis for clinical subjects. In: Paper presented at the human brain mapping

McGlashan TH, Miller TJ, Woods SW (2001) Structured interview for prodromal syndromes (SIPS; Version 3.0, unpublished manuscript). PRIME Research Clinic, Yale University, School of Medicine, New Heaven, Conneticut

Menon V (2011) Large-scale brain networks and psychopathology: a unifying triple network model. Trends Cogn Sci 15(10): 483-506. doi:10.1016/j.tics.2011.08.003

Meskaldji DE, Ottet MC, Cammoun L, Hagmann P, Meuli R, Eliez S, Thiran JP, Morgenthaler S (2011) Adaptive strategy for the statistical analysis of connectomes. PLoS One 6(8):e23009. doi:10.1371/journal.pone.0023009

Miller TJ, McGlashan TH, Rosen JL, Cadenhead K, Cannon T, Ventura J, McFarlane W, Perkins DO, Pearlson GD, Woods SW (2003) Prodromal assessment with the structured interview for prodromal syndromes and the scale of prodromal symptoms: predictive validity, interrater reliability, and training to reliability. Schizophr Bull 29(4):703-715

Minzenberg MJ, Laird AR, Thelen S, Carter CS, Glahn DC (2009) Meta-analysis of 41 functional neuroimaging studies of executive function in schizophrenia. Arch Gen Psychiatry 66(8):811-822. doi:10.1001/archgenpsychiatry.2009.91

Modinos G, Pettersson-Yeo W, Allen P, McGuire PK, Aleman A, Mechelli A (2012) Multivariate pattern classification reveals differential brain activation during emotional processing in individuals with psychosis proneness. Neuroimage 59(3): 3033-3041. doi:10.1016/j.neuroimage.2011.10.048

Modinos G, Mechelli A, Pettersson-Yeo W, Allen P, McGuire P, Aleman A (2013) Pattern classification of brain activation during emotional processing in subclinical depression: psychosis proneness as potential confounding factor. PeerJ 1:e42. doi:10.7717/ peerj. 42

Mourao-Miranda J, Reinders AA, Rocha-Rego V, Lappin J, Rondina J, Morgan C, Morgan KD, Fearon P, Jones PB, Doody GA, Murray RM, Kapur S, Dazzan P (2012) Individualized prediction of illness course at the first psychotic episode: a support vector machine MRI study. Psychol Med 42(5):1037-1047. doi:10. 1017/S0033291711002005

Murphy KC, Jones LA, Owen MJ (1999) High rates of schizophrenia in adults with velo-cardio-facial syndrome. Arch Gen Psychiatry 56(10):940-945

Murray RJ, Schaer M, Debbane M (2012) Degrees of separation: a quantitative neuroimaging meta-analysis investigating self-specificity and shared neural activation between self- and otherreflection. Neurosci Biobehav Rev 36(3):1043-1059. doi:10. 1016/j.neubiorev.2011.12.013

Opris I, Bruce CJ (2005) Neural circuitry of judgment and decision mechanisms. Brain Res Brain Res Rev 48(3):509-526. doi:10. 1016/j.brainresrev.2004.11.001

Orru G, Pettersson-Yeo W, Marquand AF, Sartori G, Mechelli A (2012) Using support vector machine to identify imaging biomarkers of neurological and psychiatric disease: a critical review. Neurosci Biobehav Rev 36(4):1140-1152. doi:10.1016/j. neubiorev.2012.01.004

Ottet MC, Schaer M, Cammoun L, Schneider M, Debbane M, Thiran JP, Eliez S (2013a) Reduced fronto-temporal and limbic connectivity in the 22q11.2 deletion syndrome: vulnerability markers for developing schizophrenia? PLoS One 8(3):e58429. doi:10.1371/journal.pone.0058429

Ottet MC, Schaer M, Debbane M, Cammoun L, Thiran JP, Eliez S (2013b) Graph theory reveals dysconnected hubs in 22q11DS and altered nodal efficiency in patients with hallucinations. Front Hum Neurosci 7:402. doi:10.3389/fnhum.2013.00402

Pettersson-Yeo W, Allen P, Benetti S, McGuire P, Mechelli A (2011) Dysconnectivity in schizophrenia: where are we now? Neurosci Biobehav Rev 35(5):1110-1124. doi:10.1016/j.neubiorev.2010. 11.004

Power JD, Barnes KA, Snyder AZ, Schlaggar BL, Petersen SE (2012) Spurious but systematic correlations in functional connectivity MRI networks arise from subject motion. Neuroimage 59(3):2142-2154. doi:10.1016/j.neuroimage.2011.10.018

Radoeva PD, Coman IL, Antshel KM, Fremont W, McCarthy CS, Kotkar A, Wang D, Shprintzen RJ, Kates WR (2012) Atlasbased white matter analysis in individuals with velo-cardiofacial syndrome (22q11.2 deletion syndrome) and unaffected siblings. Behav Brain Funct 8:38. doi:10.1186/1744-9081-8-38

Raizada RDS, Kriegeskorte N (2010) Pattern-information fMRI: new questions which it opens up and challenges which face it. Int $\mathbf{J}$ Imaging Syst Technol 20(1):31-41. doi:10.1002/ima.v20:1

Reich W (2000) Diagnostic interview for children and adolescents (DICA). J Am Acad Child Adolesc Psychiatry 39(1):59-66. doi:10.1097/00004583-200001000-00017

Richiardi J, Van De Ville D, Riesen K, Bunke H (2010) Vector space embedding of undirected graphs with fixed-cardinality vertex sequences for classification. In: Paper presented at the 20th international conference on pattern recognition (ICPR)

Richiardi J, Eryilmaz H, Schwartz S, Vuilleumier P, Van De Ville D (2011) Decoding brain states from fMRI connectivity graphs. Neuroimage 56(2):616-626. doi:10.1016/j.neuroimage.2010.05. 081

Richiardi J, Gschwind M, Simioni S, Annoni JM, Greco B, Hagmann P, Schluep M, Vuilleumier P, Van De Ville D (2012) Classifying minimally disabled multiple sclerosis patients from resting state functional connectivity. Neuroimage 62(3):2021-2033. doi:10. 1016/j.neuroimage.2012.05.078

Richiardi J, Achard S, Bunke H, Van De Ville D (2013) Machine learning with brain graphs: predictive modeling approaches for functional imaging in systems neuroscience. Sig Process Mag IEEE 30(3):58-70. doi:10.1109/msp.2012.2233865

Rihs TA, Tomescu MI, Britz J, Rochas V, Custo A, Schneider M, Debbane M, Eliez S, Michel CM (2012) Altered auditory 
processing in frontal and left temporal cortex in 22q11.2 deletion syndrome: a group at high genetic risk for schizophrenia. Psychiatry. doi:10.1016/j.pscychresns.2012.09.002

Ruhrmann S, Schultze-Lutter F, Salokangas RK, Heinimaa M, Linszen D, Dingemans P, Birchwood M, Patterson P, Juckel G, Heinz A, Morrison A, Lewis S, von Reventlow HG, Klosterkotter J (2010) Prediction of psychosis in adolescents and young adults at high risk: results from the prospective European prediction of psychosis study. Arch Gen Psychiatry 67(3):241-251. doi:10.1001/archgenpsychiatry.2009.206

Satterthwaite TD, Elliott MA, Gerraty RT, Ruparel K, Loughead J, Calkins ME, Eickhoff SB, Hakonarson H, Gur RC, Gur RE, Wolf DH (2013) An improved framework for confound regression and filtering for control of motion artifact in the preprocessing of resting-state functional connectivity data. Neuroimage 64:240-256. doi:10.1016/j.neuroimage.2012.08.052

Schaer M, Debbane M, Bach Cuadra M, Ottet MC, Glaser B, Thiran JP, Eliez S (2009) Deviant trajectories of cortical maturation in 22q11.2 deletion syndrome (22q11DS): a cross-sectional and longitudinal study. Schizophr Res 115(2-3):182-190. doi:10. 1016/j.schres.2009.09.016

Schaer M, Glaser B, Ottet MC, Schneider M, Bach Cuadra M, Debbane M, Thiran JP, Eliez S (2010) Regional cortical volumes and congenital heart disease: a MRI study in 22q11.2 deletion syndrome. J Neurodev Disord 2(4):224-234. doi:10.1007/ s11689-010-9061-4

Schmidt A, Smieskova R, Aston J, Simon A, Allen P, Fusar-Poli P, McGuire PK, Riecher-Rossler A, Stephan KE, Borgwardt S (2013) Brain connectivity abnormalities predating the onset of psychosis: correlation with the effect of medication. JAMA Psychiatry 70(9):903-912. doi:10.1001/jamapsychiatry.2013. 117

Schneider M, Debbane M, Lagioia A, Salomon R, d'Argembeau A, Eliez S (2012) Comparing the neural bases of self-referential processing in typically developing and $22 \mathrm{q} 11.2$ adolescents. Dev Cogn Neurosci 2(2):277-289. doi:10.1016/j.dcn.2011.12.004

Schreiner MJ, Karlsgodt KH, Uddin LQ, Chow C, Congdon E, Jalbrzikowski M, Bearden CE (2013) Default mode network connectivity and reciprocal social behavior in 22q11.2 deletion syndrome. Soc Cogn Affect Neurosci. doi:10.1093/scan/nst114

Shah J, Eack SM, Montrose DM, Tandon N, Miewald JM, Prasad KM, Keshavan MS (2012) Multivariate prediction of emerging psychosis in adolescents at high risk for schizophrenia. Schizophr Res 141(2-3):189-196. doi:10.1016/j.schres.2012.08.012

Shashi V, Kwapil TR, Kaczorowski J, Berry MN, Santos CS, Howard TD, Goradia D, Prasad K, Vaibhav D, Rajarethinam R, Spence E, Keshavan MS (2010) Evidence of gray matter reduction and dysfunction in chromosome 22q11.2 deletion syndrome. Psychiatry Res 181(1):1-8. doi:10.1016/j.pscychresns.2009.07.003

Shen H, Wang L, Liu Y, Hu D (2010) Discriminative analysis of resting-state functional connectivity patterns of schizophrenia using low dimensional embedding of fMRI. Neuroimage 49(4):3110-3121. doi:10.1016/j.neuroimage.2009.11.011

Shim G, Oh JS, Jung WH, Jang JH, Choi CH, Kim E, Park HY, Choi JS, Jung MH, Kwon JS (2010) Altered resting-state connectivity in subjects at ultra-high risk for psychosis: an fMRI study. Behav Brain Funct 6:58. doi:10.1186/1744-9081-6-58

Simon TJ, Ding L, Bish JP, McDonald-McGinn DM, Zackai EH, Gee J (2005) Volumetric, connective, and morphologic changes in the brains of children with chromosome 22q11.2 deletion syndrome: an integrative study. Neuroimage 25(1):169-180. doi:10.1016/j.neuroimage.2004.11.018

Simon TJ, Wu Z, Avants B, Zhang H, Gee JC, Stebbins GT (2008) Atypical cortical connectivity and visuospatial cognitive impairments are related in children with chromosome 22q11.2 deletion syndrome. Behav Brain Funct 4:25. doi:10.1186/1744-9081-4-25
Sporns O, Tononi G, Kotter R (2005) The human connectome: a structural description of the human brain. PLoS Comput Biol 1(4):e42. doi:10.1371/journal.pcbi.0010042

Sun J, Buys N (2012) Early executive function deficit in preterm children and its association with neurodevelopmental disorders in childhood: a literature review. Int $\mathrm{J}$ Adolesc Med Health 24(4):291-299. doi:10.1515/ijamh.2012.042

Sundram F, Campbell LE, Azuma R, Daly E, Bloemen OJ, Barker GJ, Chitnis X, Jones DK, van Amelsvoort T, Murphy KC, Murphy DG (2010) White matter microstructure in 22q11 deletion syndrome: a pilot diffusion tensor imaging and voxel-based morphometry study of children and adolescents. J Neurodev Disord 2(2):77-92. doi:10.1007/s11689-010-9043-6

Tohka J, Foerde K, Aron AR, Tom SM, Toga AW, Poldrack RA (2008) Automatic independent component labeling for artifact removal in fMRI. Neuroimage 39(3):1227-1245. doi:10.1016/j. neuroimage.2007.10.013

Tzourio-Mazoyer N, Landeau B, Papathanassiou D, Crivello F, Etard O, Delcroix N, Mazoyer B, Joliot M (2002) Automated anatomical labeling of activations in SPM using a macroscopic anatomical parcellation of the MNI MRI single-subject brain. Neuroimage 15(1):273-289

van Amelsvoort T, Daly E, Robertson D, Suckling J, Ng V, Critchley H, Owen MJ, Henry J, Murphy KC, Murphy DG (2001) Structural brain abnormalities associated with deletion at chromosome 22q11: quantitative neuroimaging study of adults with velo-cardio-facial syndrome. Br J Psychiatry 178:412-419

van Amelsvoort T, Schmitz N, Daly E, Deeley Q, Critchley H, Henry J, Robertson D, Owen M, Murphy KC, Murphy DG (2006) Processing facial emotions in adults with velo-cardio-facial syndrome: functional magnetic resonance imaging. Br J Psychiatry 189:560-561. doi:10.1192/bjp.bp.105.019876

van den Heuvel MP, Sporns O (2011) Rich-club organization of the human connectome. J Neurosci 31(44):15775-15786. doi:10. 1523/JNEUROSCI.3539-11.2011

van den Heuvel MP, Stam CJ, Kahn RS, Pol Hulshoff HE (2009) Efficiency of functional brain networks and intellectual performance. J Neurosci 29(23):7619-7624. doi:10.1523/JNEUR OSCI.1443-09.2009

Van Dijk KR, Sabuncu MR, Buckner RL (2012) The influence of head motion on intrinsic functional connectivity MRI. Neuroimage 59(1):431-438. doi:10.1016/j.neuroimage.2011.07.044

Van Overwalle F, Baetens K (2009) Understanding others' actions and goals by mirror and mentalizing systems: a meta-analysis. Neuroimage 48(3):564-584. doi:10.1016/j.neuroimage.2009.06. 009

Venkataraman A, Whitford TJ, Westin CF, Golland P, Kubicki M (2012) Whole brain resting state functional connectivity abnormalities in schizophrenia. Schizophr Res 139(1-3):7-12. doi:10. 1016/j.schres.2012.04.021

Vercammen A, Knegtering H, den Boer JA, Liemburg EJ, Aleman A (2010) Auditory hallucinations in schizophrenia are associated with reduced functional connectivity of the temporo-parietal area. Biol Psychiatry 67(10):912-918. doi:10.1016/j.biopsych. 2009.11.017

Volz KG, Schubotz RI, von Cramon DY (2006) Decision-making and the frontal lobes. Curr Opin Neurol 19(4):401-406. doi:10.1097/ 01.wco.0000236621.83872.71

Wechsler D (ed) (1991) Wechsler Intelligence Scale for Children. Manual, 3rd edn. Psychological Corporation, San Antonio

Wechsler D (ed) (1997) Wechsler adult intelligence scale. Administration and scoring manual, 3rd edn. Psychological Corporation, San Antonio

Whitfield-Gabrieli S, Thermenos HW, Milanovic S, Tsuang MT, Faraone SV, McCarley RW, Shenton ME, Green AI, NietoCastanon A, LaViolette P, Wojcik J, Gabrieli JD, Seidman LJ 
(2009) Hyperactivity and hyperconnectivity of the default network in schizophrenia and in first-degree relatives of persons with schizophrenia. Proc Natl Acad Sci USA 106(4):1279-1284. doi:10.1073/pnas.0809141106

Wildgruber D, Ackermann H, Kreifelts B, Ethofer T (2006) Cerebral processing of linguistic and emotional prosody: fMRI studies. Prog Brain Res 156:249-268. doi:10.1016/S0079-6123(06)56013-3

Wu K, Taki Y, Sato K, Hashizume H, Sassa Y, Takeuchi H, Thyreau B, He Y, Evans AC, Li X, Kawashima R, Fukuda H (2013) Topological organization of functional brain networks in healthy children: differences in relation to age, sex, and intelligence. PLoS One 8(2):e55347. doi:10.1371/journal.pone.0055347

Yung AR, Nelson B, Stanford C, Simmons MB, Cosgrave EM, Killackey E, Phillips LJ, Bechdolf A, Buckby J, McGorry PD (2008) Validation of "prodromal" criteria to detect individuals at ultra high risk of psychosis: 2 year follow-up. Schizophr Res 105(1-3):10-17. doi:10.1016/j.schres.2008.07.012

Zalesky A, Fornito A, Bullmore ET (2010) Network-based statistic: identifying differences in brain networks. Neuroimage 53(4):1197-1207. doi:10.1016/j.neuroimage.2010.06.041 